\title{
Hydatidosis in Morocco: Review of literature and epidemiology
}

\author{
Zineb Tlamcani \\ Department of Parasitology, Faculty of Medicine and Pharmacy of Fes, \\ University of Sidi Mohammed Ben Abdellah,Fes, Morocco,
}

Corresponding Author Zineb Tlamcani

Mobile: $+21263037764$

E mail : zineb. tlamcani@usmba.ac.m

Key words: Hydatidosis, hydatid cyst, Echinococcus granulosus, Morocco.
Hydatidosis or hydatid cyst is a prevalent zoonosis all over the world due to larval forms of the tapeworm of the genus Echinococcus. Echinococcus granulosus is the most frequent form of echinococcal infection in humans. The disease generally results from an oral ingestion of the parasite ova eliminated with feces of dogs leading to the emergence of hydatid cysts.

Hydatidosis is a health problem that may remain asymptomatic for several years. This disease is endemic in Morocco and is recorded to be a serious problem that requires great caution.

\section{INTRODUCTION}

Hydatidosis or hydatid cyst is a widespread zoonosis throughout the world due to larval forms of the tapeworm of the genus Echinococcus present in the small intestines of carnivores [1]. Infection with Echinococcus granulosus is the most frequent form of echinococcal infection in humans [2]. It is actually endemic in numerous areas of the world, like nations near to the Mediterranean Sea, in addition to northern and eastern Africa, China, South America, central as well as western Asia, and Australia [3]. The disease commonly results from an oral ingestion of the ova parasite eliminated with feces in dogs and transmitted via close contact with infected animals. Moreover, the consumption of contaminated food, which is under scrutiny, is a potential means of infection, especially in developing countries [4]. The disease is endemic in Morocco and presents a serious problem that increasingly draws attention.
Echinococcus granulosus is, known as a tapeworm, belongs to the Taeniidae family .Its adult resides in the small intestine of carnivorous definitive hosts, including dogs, coyotes, or wolves. It is a minute worm of 2 to 9 $\mathrm{mm}$ in length. It contains three or four segments and seems to have a globular scolex of $0.3 \mathrm{~mm}$ in diameter possessing a rostellum and four cuplike oval suckers. This rostellum structure is armed with a double crown of large and small hooklets. The amount of hooklets can range between 25 and 40 [5]. The scolex is succeeded by a short neck and generally only one or two immature segments; after that there is the mature segment which is the broadest and the longest. The uterus includes up to 500 eggs which are released into the feces from the ruptured segment.

Echinococcal cyst stages take place in herbivorous intermediate hosts, like camels, sheep and cattle. echinococcal cyst is a fluid-filled, rounded, unilocular cyst which contains an inner germinal layer of cells reinforced by a characteristic acellular, laminated membrane of variable thickness. Every cyst is enclosed by a hostproduced layer of granulomatous adventitial reaction. Small vesicles named brood capsules bud internally from the germinal layer and generate multiple protoscolices via asexual division [6]. Humans get infected by eating tapeworm eggs transferred from an infected carnivore. 


\section{CLINICAL FEATURE}

Accidental human infestation by larval form leads to the emergence of hydatid cysts. Generally, primary infections in humans are represented by a single cyst; nevertheless, $20-40 \%$ of persons have multiple cysts or multiple organ involvement [7]. The liver and lungs are the most commonly affected organs [8]. Less frequently involved organs are the spleen, the kidney, the heart, the bone, central nervous system, and other organs [9]. Hydatidosis is a health problem that may remain asymptomatic for several years, with symptoms generally appearing only when the cysts increase in size [10].

\section{DIAGNOSIS}

The ultimate diagnosis for mosthuman forms of hydatid disease is through physical imaging techniques, like ultrasonography, radiology, computed tomography and also magnetic resonance imaging [11]. Antibody assays are helpful to check presumptive radiologic diagnoses; however, few affected individuals with cystic echinococcosis do not reveal a detectable immune response [12]. In current times, significant efforts are already made to improve most of these techniques employing new recombinant proteins, synthetic peptides, and combinations of identified antigens. Nonetheless, regardless of the fact that immunoglobulin levels are undetectable, solely $60 \%-80 \%$ of affected people are seropositive [13]. The indirect hemagglutination test is sensitive but is currently been changed by the enzyme immunoassay (ELISA) for preliminary checking of sera. Confirmation of reactivity can be acquired by illustration of specific echinococcal antigens by immunoblot assays. Eosinophilia is found in $<25 \%$ of infected people. In seronegative persons, a presumptive diagnosis could be proved by showing protoscolices or hydatid membranes in the liquid extracted by percutaneous aspiration of the cyst [14].

\section{EPIDEMIOLOGY}

Around the world, the important endemic regions are localized in the Mediterranean peripheries: North Africa, Middle East, Greece, Turkey, Cyprus, and southern Italy and

Spain (The human infestation incidence is about 10 cases per 100,000 habitants), as well as East Africa, especially Kenya, where the incidence is the highest in the world with 220 cases per 100,000 inhabitants [15].
Current reports reveal the endemic occurrence of E. granulosus in dogs as well as in livestock and of human cases of CE in almost all North African Arabic countries which include Algeria, Libya, Egypt, and Tunisia [16]. In Algeria,annual incidence according to hospital cases has been recorded 3.6-4.6/100,000 populations [17]. The incidence of surgically proved cystic echinococcosis in eastern Libya was expected to be less than 4.2 cases per 100,000 inhabitants. [17].

This incidence is less than Tunisia which is estimated of 15 cases per 100,000 inhabitants [18]. Christine M. Budke et al reported in systematic reviews an incidence rate of 2.3,3.1, 3.35, and 18.0, 32.0/100,000 persons-year in Jordan, Palestine, Bulgaria, Kyrgyzstan and Peru respectively [19].

\section{EPIDEMIOLOGY ON MOROCCO}

The exact data on the prevalence of this disease is unknown. It is certainly underestimated due to the existence of asymptomatic forms and the low level of medicalization of the population. Thus, studies on the prevalence of hydatid disease in humans are rare and are mostly devoted to rural and operated cases [20].

The distribution of operated hydatid cyst cases in different regions of Morocco shows that the highest incidence is found in two regions: RabatSalé-Zemmours-Zaers and Meknès-Tafilalet fig1 [21].

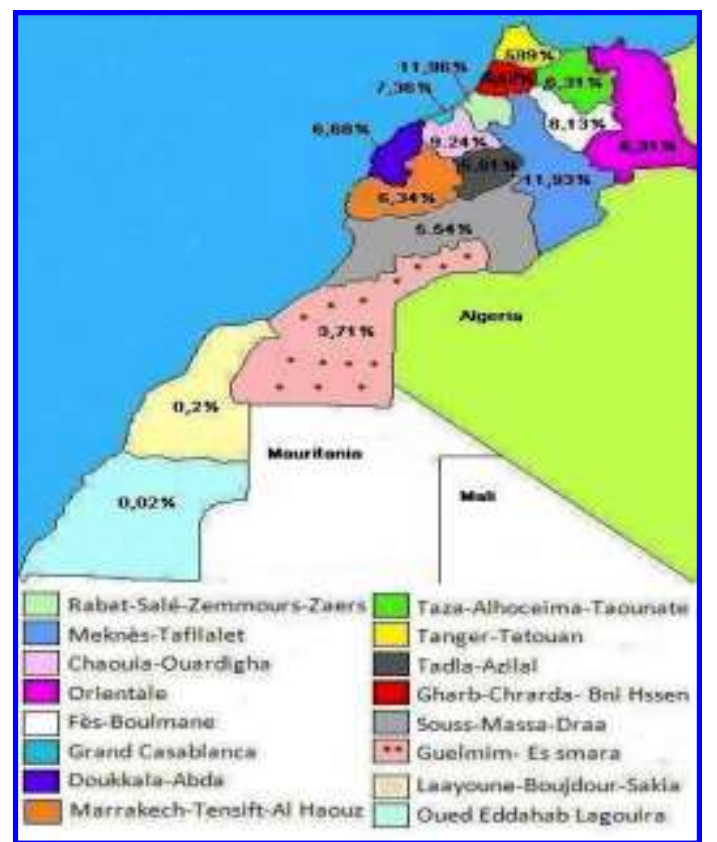

Fig (1): distribution of operated hydatid cyst cases between 1980 and 1992 in public hospitals 
Another study was carried out by Derfoufi et al to evaluate the epidemiological profile of hydatidosis in Morocco between 1980 and 2008declared an increased number of annual cases estimated to 5,2 per 100000 habitants [22].

In Morocco, the transmission of the parasite through a synanthropic cycle including dogs and livestock (sheep, cattle, camels, and Equidae). As outlined by Gemmell et al. [23], 8,470 eggs are eliminated by infected dogs daily. Therefore, there is an increased pollution of the environment with eggs. A large number of dogs (estimated of around 2 millions) and which keep the livestock in the farms live in close contact with the rural population.

The number of stray dogs in the villages and on the outskirts of cities is also a major factor in the transmission; the high percentage of the population who hardly have any knowledge about the disease and the factors of its transmission is another cause of the disease spread [24].

Sheep and cattle are the major intermediate hosts in Morocco, but sheep are considered the main source of infection to dogs and subsequently to human [25].

There are a lot of celebrations or occasions, like weddings and Aid El Kebir (the great feast) in the Muslim countries, in which the ritual homeslaughter of millions of sheep takes place (5 million sheep and goats in Morocco). This habit leads to multiplying the parasitein owned and farm dogs, which helps to preserve high infection rates in these dogs, in ruminants and in humans [26].

\section{CONCLUSION}

The risk of hydatid infection is high in rural regions where the close contact between dogs and humans is frequent. To control the disease, the measures should focus on dogs as the main factor of transmission. So it is necessary to get rid of stray dogs, deworm the suspected infected dogs as pets at home, andincinerate infected organs from dead intermediate animal hosts in addition to individual hygiene based on washing hands after gardening or touching dogs.

\section{ACKNOWLEDGEMENT}

Our acknowledgement goes to the University Hospital Center Hassan II of Fes and
Mohammed Ben Abdellah University - Fes Morocco

Funding : None

Conflicts of interest : None

\section{REFERENCES}

1- Ahmed ME, Abdelrahim MI, Ahmed FM. Hydatid disease, a morbid drop needs awareness. Sudan Med J. 2011, 47(1;4-8.

2- Al-Ani A., Elzouki AN. and Mazhar R. An Imported Case of Echinococcosis in a Pregnant Lady with Unusual Presentation. Case Reports. Infectious Diseases, 2013, 1-4.

3- Johanna W, Beate G, Suemeyra O, Richard AM, Mark MH,Tilmann G and al.Diagnostics in cystic echinococcosis: Serology versus ultrasonography. Turk J Gastroenterol. 2014, 25:398-404.

4- Ernest E, Nonga HE, Kynsieri N, Cleaveland S. A retrospectivesurvey of human hydatidosis based on hospital records duringthe period 19902003 in Ngorongoro, Tanzania. Zoonoses Public Health. 2010, 5:124-133.

5- Torgerson PR, Karaeva RR, Corkeri N, Abdyjaparov TA, Kuttubaev OT, Shaikenov BS. Human cystic echinococcosis in Kyrgystan: an epidemiological study. Acta Trop. 2003, 85:51-61.

6- Pedro M, Peter MS. Echinococcosis: a review .International Journal of Infectious Diseases. 2009, 13:125-133.

7- Kammerer WS, Schantz PM. Echinococcal disease. Infect Dis Clin North Am, 1993:7:605623.

8- McManus DP, Zhang W, Li J, Bartley PB. Echinococcosis. Lancet, 2003, 362(9392), 12951304.

9- Vahedi MA, Vahedi ML. Demographics of patients with surgicaland nonsurgical cystic echinococcosis in East Azerbaijan from 2001 to 2012. Pak J Biol Sci. 2012, 15:186-191.

10- Eckert J, Deplazes P. Biological, epidemiological, and clinical aspects of echinococcosis, a zoonosis of increasing concern. Clin Microbiol Rev. 2004, 17:107-142

11- Wenbao Zhang, Jun Li, Donald P. McManus, concepts in immunology and diagnosis ofhydatid disease. Clin Microbiol Rev. 2003, 16(1):18-36.

12- Zhang W, McManus DP. Recent advances in the immunology anddiagnosis of echinococcosis. FEMS Immunol Med Microbiol, 2006, 47:24-41.

13- Gavidia CM, Gonzales AE, Zhang W, et al. Diagnosis of cystic echinococcosis, central Peruvian Highlands. Emerg Infect Dis. 2008, 14:260-266. 
14- Hira PR, Shweiki H, Lindberg LG, Shaheen Y, Francis I, Leven H,et al. Diagnosis of cystic hydatid disease: role of aspirationcytology. Lancet 1988, 17:655-662.

15- Belamalem S, Khadmaoui A, Hami H, Harrak M, Aujjar N, Mokhtari A, Soulaymani A. Épidémiologie de l'hydatidose dansla Région du Gharb (Chrarda Beni Hssen) Maroc. Antropo. 2014, 31:33-37.

16- Eckert J, Schantz PM, Gasser RB, Torgerson PR, Bessonov AS, Movsessian SO, et al. Geographic distribution and prevalence, Eckert JGM, , In : Eckert J, Gemmell MA, Meslin FX, Pawlowski ZS, editors. WHO/OIE manual on echinococcosis in humans and animals: a public health problem of global concern. Paris' World Organisation for Animal Health; 2001, 100-142.

17- Sadjjadi SM. Present situation of echinococcosis in the Middle East and Arabic North Africa. Parasitology International, 2006, 55: 197- 202.

18- Anon. The surgical incidence rate of hydatidosis in Tunisia (1988- 1992).Report of the D.S.S.B. (Direction de Sante' et des Soins de base), Ministry Public Health. 1993.

19- Budke CM, Carabin H, Ndimubanzi PC, Nguyen H, Rainwater E, Dickey M. A Systematic Review of the Literature on Cystic Echinococcosis Frequency Worldwide and Its Associated Clinical Manifestations. Am. J. Trop. Med. Hyg. 2013, 88(6): 1011-1027.

20- EL mansourI B, laboudi M, sadak A, and Rhajaoui M. Hydatidosis human in Rabat region (Morocco): study of prevalence and contribution of serological diagnosis. International Journal of Innovation and Scientific Research, 2015, 14(2): 252-258.
21- Comité interministériel de lutte contre l'hydatidose/ echinococcose. Lutte Contre l'hydatidose echinococcose, Guide des activités de lute, 2007.

22- Derfoufi O, Ngoh EA, Elmaataoui A, Miss EM, Esselmani H, Lyagoubi M, Aoufi S. Epidemiological profile of cystic echinococcosis in Morocco from 1980 to 2008. Ann Biol Clin, 2012, 70 (4):457-461.

23- Gemmell MA, Roberts MG, Beard TC and Lawson JR, Quantitative epidemiology and transmission dynamics with special reference to Echinococcus granulosus, In WHO/OIE Manual on Echinococcosis in Humans and Animals: A Public Health Problem of Global Concern, J. Eckert, M. A. Gemmell, F. F. X. Meslin, and Z. S. Pawlowski, Eds, OIE, Paris, France, 2001:143156.

24- Azlaf R, Dakkak A. Epidemiological study of the cystic echinococcosisin Morocco. Vet Parasitol, 2006:137, 83-93.

25- El Berbri I, Petavy AF, Umhang G, Bouslikhane M, Fassi Fihri O, Boué F, and Dakkak A. Epidemiological Investigations on Cystic Echinococcosis in North-West (Sidi Kacem Province) Morocco: Infection in Ruminants. Advances in Epidemiology, 2015: 1-9.

26- Dakkak A. Echinococcosis/hydatidosis: A severe threat in Mediterranean countries.Vet. Parasitol. 2010, 174(1):2-11.

Peer reviewer: Samia Etewa; Professor of Parasitology, Faculty of Medicine, Zagazig University, Egypt.

Editor: Tarik Zaher;Professor of Tropical Medicine, Faculty of Medicine, Zagazig University, Egypt. 